\title{
Symptomatic Cryptococcal Meningitis with Negative Serum and Cerebrospinal Fluid Cryptococcal Antigen Tests
}

\author{
Vivien Nanfuka ${ }^{\mathrm{l} *}$ \\ Mkhoi L Mkhoi (iD ${ }^{2-4, *}$ \\ Jane Gakuru ${ }^{2}$ \\ Richard Kwizera (iD ${ }^{2}$ \\ Joseph Baruch Baluku (D) ${ }^{5}$ \\ Felix Bongomin (iD) 6,7 \\ David B Meya ${ }^{1,2,6}$ \\ 'Infectious Diseases Unit, Kiruddu \\ National Referral Hospital, Kampala, \\ Uganda; ${ }^{2}$ Infectious Diseases Institute, \\ College of Health Sciences, Makerere \\ University, Kampala, Uganda; ${ }^{3}$ Mark \\ Wainberg Fellowship Programme, \\ Infectious Diseases Institute, College of \\ Health Sciences, Makerere University, \\ Kampala, Uganda; ${ }^{4}$ Department of \\ Microbiology and Parasitology, College of \\ Health Sciences, University of Dodoma, \\ Dodoma, Tanzania; ${ }^{5}$ Division of \\ Pulmonology, Kiruddu National Referral \\ Hospital, Kampala, Uganda; ${ }^{6}$ Department \\ of Medicine, School of Medicine, College \\ of Health Sciences, Makerere University, \\ Kampala, Uganda; ${ }^{7}$ Department of \\ Medical Microbiology, Faculty of \\ Medicine, Gulu University, Gulu, Uganda
}

*These authors contributed equally to this work

\begin{abstract}
Background: Cryptococcal meningitis is a leading cause of mortality in advanced HIV disease. A positive cerebrospinal fluid cryptococcal antigen ( $\mathrm{CrAg}$ ) test defines cryptococcal meningitis. Herein, we present a patient with serum and cerebrospinal fluid $\mathrm{CrAg}$ negative cryptococcal meningitis, despite a positive cerebrospinal fluid India ink examination and quantitative culture.
\end{abstract}

Case Details: A 56-year-old HIV-positive Ugandan woman, with an undetectable HIV RNA viral load and CD4+ T-cell count of 766 cells per microlitre presented with signs and symptoms consistent with cryptococcal meningitis. Her serum and cerebrospinal fluid $\mathrm{CrAg}$ tests were negative despite having a positive cerebrospinal fluid India ink and quantitative culture. On day 1 , she was commenced on intravenous amphotericin B deoxycholate (1mg/ $\mathrm{kg}$ ) for 3 days (considering $10 \mathrm{CFU}$ growth of Cryptococcus spp) in combination with oral flucytosine $(100 \mathrm{mg} / \mathrm{kg})$ for 7 days and then fluconazole $1200 \mathrm{mg}$ once daily for the next 11 days. By day 7 , she was symptom free and quantitative cerebrospinal fluid culture was negative for Cryptococcus spp. She was discharged on day 9. At 10 weeks (day +40$)$ and 18 weeks (day +72$)$, she was well and adherent to her antiretroviral therapy and on maintenance phase of cryptococcal meningitis on fluconazole at a dose of $400 \mathrm{mg}$ once daily.

Conclusion: This report alerts clinicians managing patients with HIV-associated cryptococcal meningitis to four uncommon clinical scenarios; first, the possibility of negative serum and cerebrospinal fluid $\mathrm{CrAg}$ lateral flow assay results in the context of low cerebrospinal fluid fungal burden in a symptomatic patient. Second, possible occurrence of cryptococcal meningitis in a patient with high CD4 T-cell lymphocyte counts. Third, an early seroconversion of cryptococcal antigenaemia following effective fluconazole therapy. Fourth, an early symptomatic relapse of cryptococcal meningitis albeit negative serum $\mathrm{CrAg}$.

Keywords: cryptococcal antigen test, cryptococcal meningitis, amphotericin B, fluconazole, flucytosine, India ink

\section{Introduction}

Despite the global roll-out of antiretroviral therapy, cryptococcal meningitis, predominantly caused by Cryptococcus neoformans remain one of the leading cause of death among human immunodeficiency virus (HIV) infected persons in subSaharan Africa. ${ }^{1}$ Globally, cryptococcal meningitis accounts for $15-20 \%$ of deaths among persons with advanced HIV disease. ${ }^{1}$ Cryptococcal meningitis is an opportunistic infection that occurs due to T-cell deficiency and is frequently diagnosed in patients with CD4+ T-cell count below 200 cells/microliter. $^{2}$
Correspondence: Felix Bongomin Department of Medical Microbiology, Faculty of Medicine, Gulu University, Gulu, Uganda

Tel +256-784-523-395

Email drbongomin@gmail.com 
Point-of-care diagnostic assays, particularly the cryptococcal antigen (CrAg) lateral flow assay (LFA) have revolutionized the diagnosis of cryptococcal meningitis. A positive serum $\mathrm{CrAg}$ precedes overt cryptococcal meningitis by several weeks presenting a window for $\mathrm{CrAg}$ screening and pre-emptive fluconazole therapy to halt progression to cryptococcal meningitis. ${ }^{3}$ The detection of cryptococcal disease via $\mathrm{CrAg}$ testing has become an essential tool in the armamentarium of cryptococcal meningitis. $\mathrm{CrAg}$ can be detected in serum, plasma, whole blood, and in cerebrospinal fluid in those with cryptococcal meningitis. ${ }^{4}$ With sensitivity and specificity close to $100 \%, \mathrm{CrAg}$ testing has thus become the new "gold standard" for the diagnosis of cryptococcal meningitis. ${ }^{5}$

A small proportion of cryptococcal meningitis cases in Uganda have occurred in individuals with relatively higher CD4 + T-cell count ${ }^{6}$ and some of these patients may have a negative cerebrospinal fluid or blood CrAg tests. Herein, we present a patient with serum and cerebrospinal fluid $\mathrm{CrAg}$ negative cryptococcal meningitis, despite a positive cerebrospinal fluid India ink examination and quantitative culture.

\section{Case Presentation}

In February 2021 (day 0), a 56-year-old Ugandan woman presented to the Infectious Disease Unit of Kiruddu National Referral Hospital, Uganda, with a two-month history of mild-to-moderate, on-and-off headaches, which were worse in the mornings and were associated with neck pain, nausea, and blurred vision. She denied any history of convulsions, fever, vomiting, photophobia, diplopia, altered level of consciousness or impaired hearing.

Her past medical history is significant for HIV-1 infection diagnosed in 2006 for which she was commenced on Zidovudine (AZT), Lamivudine (3TC) and Efavirenz (EFV) as first-line antiretroviral therapy. She was also diagnosed with systemic arterial hypertension in 2014, managed with bendroflumethiazide (5 $\mathrm{mg}$ once daily). She reported good adherence to antiretroviral therapy as well as her antihypertensive medication.

Her initial antiretroviral therapy regimen (AZT/3TC/EFV) was programmatically switched to Tenofovir Disoproxil Fumarate (TDF), 3TC, and Dolutegravir (DTG) regimen and her cotrimoxazole (CTX) prophylaxis discontinued in May 2019 since she had undetectable HIV RNA viral load and her CD4+ T-cell count at the time was 767 cells per microliter. In January 2020 (day -364), she was diagnosed with asymptomatic cryptococcal antigenemia (she had a positive serum $\mathrm{CrAg}$ and a negative cerebrospinal fluid
$\mathrm{CrAg}$ ). She completed 24 weeks of fluconazole and was well and asymptomatic. Eight months prior to admission (day -224), she received isoniazid as tuberculosis preventive therapy.

On admission (day 0), her vitals were as follows: axillary temperature $-36.0^{\circ} \mathrm{C}$, pulse rate -83 beats per minute, blood pressure $-130 / 74 \mathrm{mmHg}$ and respiratory rate - 14 breaths per minute. On further physical exam, she was in fair general condition, conscious and alert, and fully oriented in person, place and time.

Neurological exam revealed a Glasgow coma scale of $15 / 15$, no obvious craniopathies, her neck was stiff. However, both Kernig's and Brudzinski's signs were negative. Muscle tone, bulk, tendon reflexes, and sensation were normal. Other systemic examination was unremarkable.

On day 0 , both serum and cerebrospinal fluid $\mathrm{CrAg}$ lateral flow assay tests (IMMY, Oklahoma, USA) were negative, despite serial dilutions. CD4+ T-cell count was 766 cells/microliter and HIV RNA viral load was undetectable abdominal ultrasound and chest $\mathrm{x}$-ray were nor$\mathrm{mal}$ and the Urine lipoarabinomannan lateral flow assay was negative. Given the high index of suspicion, a lumbar puncture was ordered and results are as shown in Table 1.

Her admission hemoglobin was $12.8 \mathrm{~g} / \mathrm{dL}$, platelet 219 $\times 10^{\wedge} 3 / \mu \mathrm{L}$ and white cell count of $5.5 \times 10^{\wedge} 3 / \mu \mathrm{L}$ with normal differentials. The rest of the full hemogram parameters were normal. Baseline renal and liver biochemistries were within normal limits.

India ink preparation and quantitative cultures on Sabouraud agar were suggestive of Cryptococcus spp, (Figure 1) supporting the diagnosis of cryptococcal meningitis.

On day 1 , she was commenced on intravenous amphotericin B deoxycholate $(1 \mathrm{mg} / \mathrm{kg}$ ) for 3 days (considering $10 \mathrm{CFU}$ growth of Cryptococcus spp) in combination with oral flucytosine $(100 \mathrm{mg} / \mathrm{kg})$ for 7 days and then fluconazole $1200 \mathrm{mg}$ once daily for the next 11 days.

By day 7 , she was symptom free and quantitative cerebrospinal fluid culture was negative for Cryptococcus spp. She was discharged on day 9. At 10 weeks (day +40$)$ and 18 weeks (day +72), she was well and adherent to her antiretroviral therapy and on maintenance phase of cryptococcal meningitis on fluconazole at a dose of $400 \mathrm{mg}$ once daily.

\section{Discussion}

The present case report seeks to alert clinicians managing patients with HIV-associated cryptococcal meningitis to four uncommon clinical scenarios; first, the possibility of 
Table I Summary of Cerebrospinal Fluid Analysis

\begin{tabular}{|l|l|l|l|l|}
\hline Parameter & Normal Ranges & Day $\mathbf{0}$ & Day 3 & Day 7 \\
\hline Opening pressure & $5-20 \mathrm{~cm}$ of water & $15 \mathrm{~cm}$ of water & $9 \mathrm{~cm}$ of water & $7 \mathrm{~cm}$ of water \\
\hline Cerebrospinal fluid appearance & Clear and colorless & Clear and colorless & Clear and colorless & Clear and colorless \\
\hline Closing pressure & $5-20 \mathrm{~cm}$ of water & $14 \mathrm{~cm}$ of water & Not measured & Not measured \\
\hline Volume collected & $150 \mathrm{mls}$ & $5 \mathrm{mls}$ & $3 \mathrm{mls}$ & $2 \mathrm{mls}$ \\
\hline Glucose & $2.5-3.5 \mathrm{mmol} / \mathrm{L}$ & $3.2 \mathrm{mmol} / \mathrm{L}$ & $2.8 \mathrm{mmol} / \mathrm{L}$ & $3.2 \mathrm{mmol} / \mathrm{L}$ \\
\hline Lactate & $<2.5 \mathrm{mmol} / \mathrm{L}$ & $2.7 \mathrm{mmol} / \mathrm{L}$ & $2.8 \mathrm{mmol} / \mathrm{L}$ & $1.6 \mathrm{mmol} / \mathrm{L}$ \\
\hline CrAg & Negative & Negative & Negative & Negative \\
\hline India Ink & Sterile & Encapsulated budding yeast cells & Negative & Negative \\
\hline Gram stain & Sterile & No bacteria seen & No bacteria seen & No bacteria seen \\
\hline Quantitative culture & Sterile & $10 \mathrm{cfu} / \mathrm{mL}$ of Cryptococcus spp. & No growth & No growth \\
\hline Total white cell count & $0-5$ cells $/ \mathrm{mm}^{3}$ & $<5$ cells $/ \mathrm{mm}^{3}$ & $<5$ cells/mm ${ }^{3}$ & $<5$ cells/mm ${ }^{3}$ \\
\hline Total protein & $15-60 \mathrm{mg} / \mathrm{dL}$ & $22.1 \mathrm{mg} / \mathrm{dL}$ & $21.5 \mathrm{mg} / \mathrm{dL}$ & $24.2 \mathrm{mg} / \mathrm{dL}$ \\
\hline Ziehl-Neelsen stain & Sterile & No acid-fast bacilli seen & No acid-fast bacilli seen & No acid-fast bacilli seen \\
\hline
\end{tabular}

Abbreviation: CFU, colony forming unit.

negative serum and cerebrospinal fluid $\mathrm{CrAg}$ lateral flow assay results in the context of low cerebrospinal fluid fungal burden in a symptomatic patient. Second, possible occurrence of cryptococcal meningitis in a patient with high CD4 T-cell lymphocyte counts. Third, an early seroconversion of cryptococcal antigenaemia following effective fluconazole therapy. Fourth, an early symptomatic relapse of cryptococcal meningitis albeit negative serum $\mathrm{CrAg}$. We were unable to find relevant explanation of these observations in the literature.

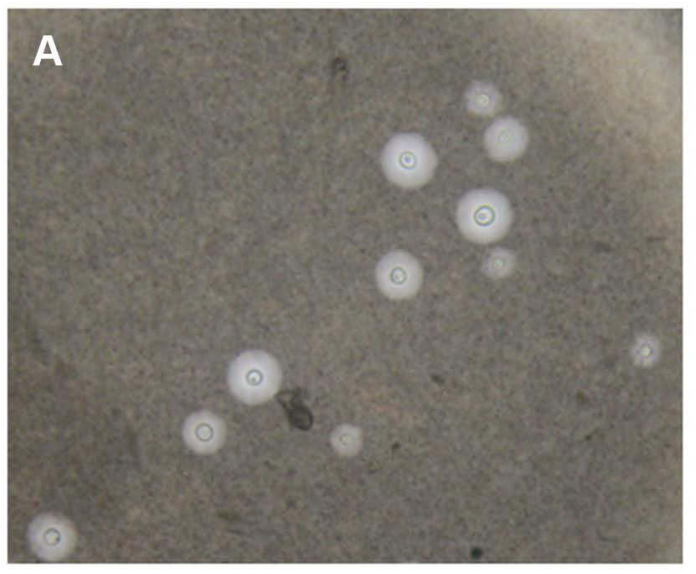

Clinical validation studies have supported widespread use of the lateral flow assay owing to high sensitivity and specificity for detecting $\mathrm{CrAg}$ in both serum and cerebrospinal fluid specimens. ${ }^{7}$ This has revolutionized diagnosis and management of HIV-associated cryptococcal antigenemia and cryptococcal meningitis in resourcelimited countries, which bear the greatest burden of the condition. ${ }^{1,8}$ Detectable cryptococcal antigenemia precedes meningitis symptoms by $3-4$ weeks; ${ }^{3}$ thus, atypical presentation as was the case in this patient may complicate

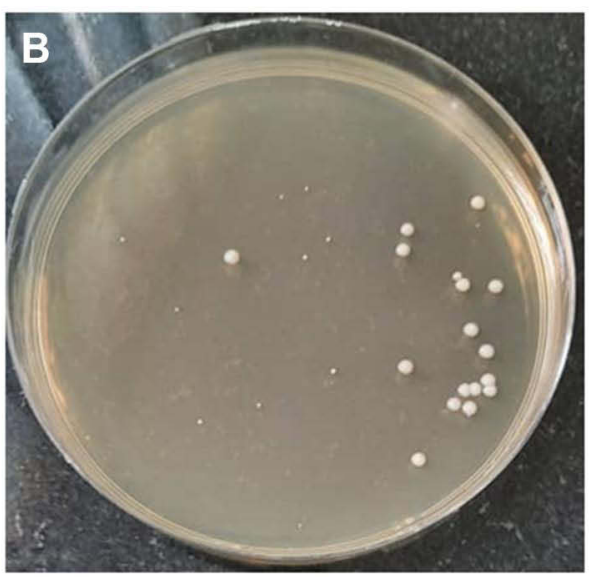

Figure I India ink preparation demonstrating encapsulated yeast cells $(\mathbf{A})$ and creamy growth of yeasts on Sabouraud agar of approximately 10 colony forming units/mL of cerebrospinal fluid $\mathbf{( B )}$. 
treatment decisions in places where LFA are the only available diagnostic options. It is therefore prudent that clinicians lacking access to cryptococcal cerebrospinal fluid culture maintain a high index of suspicion for cryptococcal meningitis when managing previously treated symptomatic patients with negative serum and cerebrospinal fluid CrAg tests.

The decision to start antifungal therapy for a patient with negative serum and cerebrospinal fluid CrAg tests is further complicated by concerns for potential drug-related toxicity ${ }^{9}$ and overlapping presentation of other HIVassociated CNS infections in this setting. ${ }^{10}$ However, the presence of meningitis symptoms, prior history of preemptive treatment for cryptococcal antigenemia and low quantitative cerebrospinal fluid cultures in this patient were helpful in alerting the attending clinicians to the possibility of cryptococcal meningitis disease and initiating appropriate antifungal therapy.

Negative serum and cerebrospinal fluid lateral flow assay test results could be explained by very low titers and/or false-negative results. ${ }^{11}$ Given the pathophysiology of cryptococcosis, ${ }^{12}$ it is unlikely that low fungal burden would disseminate haematogenously and result in development of meningitis symptoms as was the case in this patient. There have been several reports in the literature of falsenegative serum or cerebrospinal fluid $\mathrm{CrAg}$ tests due to the "high hook" effect where high concentration of the CrAg results in decreased intensity of the test lines on the lateral flow assay. ${ }^{11}$ In our case, this possibility was ruled out by repeat testing and serial dilution of both serum and cerebrospinal fluid samples, which showed the same negative results. Furthermore, the CrAg lateral flow assay used in this patient is rarely associated with false-negative results. ${ }^{13}$

\section{Conclusion}

In summary, cryptococcal meningitis is common among patients with CD4 $\mathrm{T}$ cell counts $<100$ cells $/ \mathrm{mm}^{3}$ and as a result, the World Health Organization (WHO) guidelines recommend screening for serum $\mathrm{CrAg}$ in people living with HIV (PLHIV) with CD4 T cell counts $\leq 100$ cells $/ \mathrm{mm}^{3}$ and conditionally in those with CD4 T cell counts $\leq 200$ cells/ $\mathrm{mm}^{3} .{ }^{14}$ Our patient had CD4 T cell count of 766 cells per microliter, which is far above the locally recommended threshold for screening which is $\leq 200$ cells $/ \mathrm{mm}^{3}$. Rare occurrence of cryptococcal disease in patients with CD4 $\mathrm{T}$ cell counts $>100$ cells $/ \mathrm{mm}^{3}$ has been reported ${ }^{6}$ and may be a result of strong immune response leading to excessive inflammation and tissue damage as suggested in the damage- response framework. ${ }^{15}$ In support of this theory is the laboratory finding of high CD4+ T-cell count observed in this patient; however, a cerebrospinal fluid count below 5 cells $/ \mathrm{mm}^{3}$ vastly contradicts this observation.

\section{Ethics}

The patients provided an informed written consent for this case to be published in a peer-reviewed journal. This case was written up as part of routine quality improvement audit and clinical care. As such, institutional approval was not required.

\section{Acknowledgments}

The patient and all our colleagues at the Infectious Diseases Unit, Kiruddu National Referral Hospital, Kampala, Uganda

\section{Author Contributions}

All authors contributed to data analysis, drafting or revising the article, have agreed on the journal to which the article will be submitted, gave final approval of the version to be published, and agree to be accountable for all aspects of the work.

\section{Disclosure}

The authors report no conflicts of interest in this work.

\section{References}

1. Rajasingham R, Rachel MS, Benjamin JP, et al. Global burden of disease of HIV-associated cryptococcal meningitis: an updated analysis. Lancet Infect Dis. 2017;3099(17):1-9.

2. Perfect JR, Dismukes WE, Dromer F, et al. Clinical practice guidelines for the management of cryptococcal disease: 2010 update by the Infectious Diseases Society of America. Clin Infect Dis. 2010;50 (3):291-322. doi:10.1086/649858

3. French N, Gray K, Watera C, et al. Cryptococcal infection in a cohort of HIV-1-infected Ugandan adults. Aids. 2002;16:1031-1038. doi:10.1097/00002030-200205030-00009

4. Bongomin F, Govender NP, Chakrabarti A, et al. Essential in vitro diagnostics for advanced HIV and serious fungal diseases: international experts' consensus recommendations. Eur J Clin Microbiol Infect Dis. 2019;38(9):1581-1584. doi:10.1007/s10096-019-03600-4

5. Boulware DR, Rolfes MA, Rajasingham R, et al. Multisite validation of cryptococcal antigen lateral flow assay and quantification by laser thermal contrast. Emerg Infect Dis. 2014;20(1):45-53. doi:10.3201/ eid2001.130906

6. Tugume L, Rhein J, Hullsiek KH, et al. HIV-associated cryptococcal meningitis occurring at relatively higher CD4 counts. $J$ Infect Dis. 2019;219(6):877-883. doi:10.1093/infdis/jiy602

7. Rajasingham R, Boulware DR. HIV care: ART adherence support and cryptococcal screening. Lancet. 2015;385(9983):2128-2129. doi:10.1016/S0140-6736(15)60455-X

8. Oladele R, Bongomin F, Gago S, Denning D. HIV-associated cryptococcal disease in resource-limited settings: a case for "prevention is better than cure"? J Fungi. 2017;3(4):67. doi:10.3390/jof3040067

9. Vanselow M, Brandt ME, Park BJ. Diagnosis and management of cryptococcal disease in resource-limited settings. Curr Fungal Infect Rep. 2012;6(1):35-40. doi:10.1007/s12281-011-0082-6 
10. Asif S, Bennett J, Pauly RR. A unique case of Cryptococcus and histoplasmosis co-infection in an HIV-negative male on chronic steroid therapy. Cureus. 2019;11(5).

11. Kozel TR, Bauman SK. CrAg lateral flow assay for cryptococcosis. Expert Opin Med Diagn. 2012;6(3):245-251. doi:10.1517/ 17530059.2012.681300

12. Jarvis JN, Percival A, Bauman S, et al. Evaluation of a novel point-of-care cryptococcal antigen test on serum, plasma, and urine from patients with HIV-associated cryptococcal meningitis. Clin Infect Dis. 2011;53(10):1019-1023. doi:10.1093/cid/cir613

13. Temfack E, Rim JJB, Spijker R, et al. Cryptococcal antigen in serum and cerebrospinal fluid for detecting cryptococcal meningitis in adults living with human immunodeficiency virus: systematic review and meta-analysis of diagnostic test accuracy studies. Clin Infect Dis. 2021;72:1268-1278.
14. World Health Organisation. Guidelines for the diagnosis, prevention and management of cryptococcal disease in HIV-infected adults, adolescents and children. World Health Organisation; 2018.

15. Pirofski LA, Casadevall A. Immune-mediated damage completes the parabola: Cryptococcus neoformans pathogenesis can reflect the outcome of a weak or strong immune response. MBio. 2017;8:e206317. doi:10.1128/mBio.02063-17

\section{Publish your work in this journal}

HIV/AIDS - Research and Palliative Care is an international, peerreviewed open-access journal focusing on advances in research in HIV, its clinical progression and management options including antiviral treatment, palliative care and public healthcare policies to control viral spread. The manuscript management system is completely online and includes a very quick and fair peer-review system, which is all easy to use. Visit http://www.dovepress.com/testimonials.php to read real quotes from published authors. 